\title{
Multiple venous anastomoses decrease the need for intensive postoperative management in tamai zone I replantations
}

\author{
Deok Hyeon Ryu, Si Young Roh, Jin Soo Kim, Dong Chul Lee, Kyung Jin Lee \\ Department of Plastic Surgery, Gwangmyeong Sungae General Hospital, Gwangmyeong, Korea
}

Background Venous anastomosis is an important component of digital replantation, but is not always feasible, as some cases require external bleeding to treat venous congestion in the replanted tissue. In the present study, we evaluated the relationship between the number of vein anastomoses and the survival rate of Tamai zone I replantations.

Methods A retrospective review was performed of all patients who underwent replantation of a fingertip amputation between 2014 and 2016. Patient charts were reviewed for demographic information, the mechanism of injury, the number of venous anastomoses, and the use of anticoagulation, external bleeding, and/or leeches. The cohort was divided into 3 groups depending on the number of venous anastomoses: no veins (group 1), a single vein (group 2), and 2 or more veins (group 3). Survival rates and external bleeding rates were analyzed across the groups.

Results The review identified 143 fingertip replantations among 134 patients. The overall survival rate was 94\% (135 of 143). Failures were due equally to venous complications ( $n=4$, $50 \%)$ and to arterial complications $(n=4,50 \%)$. Our analysis did not identify any correlation between the number of veins anastomosed and the replant survival rate $(P=0.689)$. However, a greater number of anastomoses was associated with a significantly lower frequency of external bleeding $(\mathrm{P}=0.017)$.

Conclusions The number of venous anastomoses was not correlated with the survival rate. However, a greater number of venous anastomoses was associated with a decreased need for external bleeding, corresponding to a significant decrease in the need for postoperative monitoring and leech therapy.

Keywords Veins / Anastomosis / Replantation / Finger / Amputation
Correspondence: Si Young Roh Department of Plastic and Reconstructive Surgery, Gwangmyeong Sungae General Hospital, 36 Digital-ro, Gwangmyeong 14241, Korea

Tel: +82-2-2680-7637

Fax: +82-2-2615-7218

E-mail: psczero@gmail.com

The authors deeply appreciate Dr. Aram Harijan for his insight and assistance in the preparation of this manuscript.

This article was presented at PRS Korea 2016 on November 17, 2016, in Seoul, Korea.

Received: 13 Jun 2017 • Revised: 19 0ct 2017 • Accepted: 20 0ct 2017

pISSN: 2234-6163 • elSSN: 2234-6171 • https://doi.org/10.5999/aps.2017.01018 • Arch Plast Surg 2018;45:58-61

\section{INTRODUCTION}

Fingertip amputation has been always been a difficult problem in hand surgery. In the past, the amputated fingertip stump was treated with a multitude of reconstructive techniques, such as the V-Y advancement flap, thenar flap, cross-finger flap, and vascular island flap [1]. With the advent of microsurgery, vessel anastomosis became possible to the point of the smallest vessels being considered worthwhile targets, and this allowed the first attempts at fingertip replantation. Over the past few decades, 
fingertip replantation has been found to lead to improvements in functional, psychological, and aesthetic assessments [2-4].

Of all the technical challenges involved in fingertip replantation, venous anastomosis remains the most difficult due to the small caliber of the vessels and the friable nature of the vessel walls. Therefore, fingertip replantation has been attempted with arterial anastomosis, but without any venous repair [5-8]. Additionally, venorrhaphy is more technically demanding than arteriorrhaphy. Attempting venorrhaphy increases the overall operative time and the risk of arterial spasm [7,9], which must weighed against the suggestion by Aksoy et al. [10] that venorrhaphy does not necessarily solve the problem of venous congestion. As such, venorrhaphy is considered to be optional in Tamai zone I replantation.

In this study, we evaluated whether a greater number of vein repairs was associated with an improved replant survival rate and how venous repair changed the clinical course of patients with fingertip amputation.

\section{METHODS}

A single-institution retrospective review was performed of all patients who underwent Tamai zone I replantation between January 2014 and May 2016. Patient charts were reviewed for demographic information, the mechanism of injury, the number of arterial and venous anastomoses, and the use of anticoagulation, external bleeding, and/or leeches. External bleeding was performed by partial de-epithelialization of the flap skin. Patients were excluded if they did not return for follow-up visits. The primary outcome was survival of the replanted fingertip at discharge from the hospital. A replanted digit was considered viable if the capillary refill time was within the normal range.

Each replanted digit was assigned to one of 3 groups according to the number of vein anastomoses: no venous anastomosis (group 1), a single venous anastomosis (group 2), and 2 or more venous anastomoses (group 3).

Our statistical analysis included a comparison of proportions using the chi-square test. $P$-values $<0.05$ were considered to indicate statistical significance, and relative risks with $95 \%$ confidence intervals were calculated.

\section{RESULTS}

The review identified a total of 143 Tamai zone I replantations in 134 patients. The operations were performed by 1 of 4 boardcertified surgeons with an average of 16.5 years of experience. In each case, venous anastomosis was attempted whenever the vein ends could be identified and were in a repairable state.
The mean age of the patients was 40.3 years (range, 1-72 years); 106 patients were male and 28 were female (Table 1 ). Crush injuries were the most common type of injury mechanism $(n=111,78 \%)$, and the remaining cases were clean-cut injuries $(n=32,22 \%)$ (Table 2). The anatomic distribution was fairly representative of fingertip injuries, with the index finger being the most commonly injured $(n=46)$, followed by the ring finger (31), long finger (29), small finger (21), and thumb (16).

Venous anastomosis was not possible in 69 replantations (group 1). A single venous anastomosis was performed in 43 digits (group 2). Two or more veins were anastomosed in 31 digits (group 3). The mean tourniquet duration was 1.4 hours (range, $0.3-3$ hours).

During the postoperative period, intravenous prostaglandin E1 and a heparin drip were administered to all patients. None of the patients in our review had contraindications (e.g., heparininduced thrombocytopenia) that would preclude the treatment, and all 134 patients underwent an intravenous heparin drip (2,000 units every 4 hours for 6 days). The replanted digits were monitored for venous congestion. Discoloration of the replanted digit was considered to be suspicious of venous congestion and prompted a pinprick test. If the blood from the pinprick was dusky (i.e., not bright red), a de-epithelialized pit was created in the replanted tissue using a \#15 blade. If bleeding from the deepithelialized pit was not sufficient for resolving the decongestion (i.e., continued discoloration was noted), leech therapy was used until the resolution of decongestive signs.

External bleeding was performed in 58 digits (Table 3). The

\section{Table 1. Patient demographics}

\begin{tabular}{|lcccc|}
\hline No. of veins & Total & Male & Female & Age $(\mathbf{y r})$ \\
\hline 0 & 69 & 50 & 19 & 36.8 \\
1 & 43 & 32 & 11 & 44.8 \\
$2+$ & 31 & 27 & 4 & 39.3 \\
\hline
\end{tabular}

\section{Table 2. Mechanism of injury}

\begin{tabular}{|lccc|}
\hline No. of veins & Total & Clean-cut & Crush \\
\hline 0 & 69 & 17 & 52 \\
1 & 43 & 9 & 34 \\
$2+$ & 31 & 7 & 24 \\
\hline
\end{tabular}

\begin{tabular}{|c|c|c|c|}
\hline Total & $\begin{array}{l}\text { With external } \\
\text { bleeding }\end{array}$ & $\begin{array}{c}\text { Without external } \\
\text { bleeding }\end{array}$ & $\begin{array}{l}\text { External } \\
\text { bleeding rate } \\
(\%)\end{array}$ \\
\hline 143 & 58 & 85 & 40.6 \\
\hline
\end{tabular}


Table 4. Survival rates of digits with external bleeding and leech usage

\begin{tabular}{|lcccc|}
\hline External bleeding & Total & $\begin{array}{c}\text { Salvaged } \\
\text { digits }\end{array}$ & $\begin{array}{c}\text { Nonviable } \\
\text { digits }\end{array}$ & $\begin{array}{c}\text { Survival } \\
\text { rate (\%) }\end{array}$ \\
\hline $\begin{array}{l}\text { Total external bleeding } \\
\text { External bleeding plus } \\
\text { leech therapy }\end{array}$ & 58 & 53 & 5 & 91.4 \\
\hline
\end{tabular}

Table 5. External bleeding rate according to the number of replanted veins

\begin{tabular}{|lccccc|}
\hline $\begin{array}{l}\text { No. of } \\
\text { veins }\end{array}$ & Total & $\begin{array}{c}\text { With } \\
\text { external } \\
\text { bleeding }\end{array}$ & $\begin{array}{c}\text { Without } \\
\text { external } \\
\text { bleeding }\end{array}$ & $\begin{array}{c}\text { External } \\
\text { bleeding } \\
\text { rate (\%) }\end{array}$ & P-value \\
\hline 0 & 69 & 35 & 34 & 50.7 & 0.017 \\
1 & 43 & 17 & 26 & 39.5 & \\
$2+$ & 31 & 6 & 25 & 19.4 & \\
\hline a) Chi-square test. & & & & \\
\hline
\end{tabular}

Table 6. Survival rate according to the number of replanted veins

\begin{tabular}{|lccccc|}
\hline $\begin{array}{l}\text { No. of } \\
\text { veins }\end{array}$ & Total & Survival & Failure & $\begin{array}{c}\text { Survival } \\
\text { rate (\%) }\end{array}$ & P-value $^{\text {a) }}$ \\
\hline 0 & 69 & 65 & 4 & 94.2 & 0.689 \\
1 & 43 & 40 & 3 & 93.0 & \\
$2+$ & 31 & 30 & 1 & 96.8 & \\
\hline a) Chi-square test. & & & & \\
\hline
\end{tabular}

duration of external bleeding ranged from 1 to 9 days, with an average of 4.3 days. External bleeding was used without leech therapy for 14 digits, whereas leeches were used in conjunction with external bleeding for 44 digits. The survival rate did not significantly differ depending on the use of leech therapy $(P>0.05)$ (Table 4). The number of venous anastomoses was associated with a decreased requirement for external bleeding $(\mathrm{P}=0.017)$ (Table 5). The overall survival rate for replanted digits was $94 \%$ (135 of 143 replantations). No statistically significant relationship was detected between the number of venous anastomoses and replant survival $(\mathrm{P}=0.689)$ (Table 6). Among the 8 failed replantations, arterial insufficiency was the cause in 4 cases (50\%), and the remaining 4 failures were due to venous congestion.

\section{DISCUSSION}

In free flap transfer, vessel anastomosis serves as a temporary way to provide blood supply until the process of neovascularization is completed in the newly grafted tissue. This phenomenon can be observed in the division of the anterolateral thigh bridge flap, in which not all divisions are supplied and drained by the anastomosed vessel. Likewise, vessel anastomosis is a temporary means of survival for replanted tissues. In digital replantation, this problem of survival until neovascularization is exemplified by the issue of venous congestion in Tamai zone I replantations.

At the interface between the fingertip stump and the amputated tissue, the veins have an extremely small diameter, and the pedicle length is minimal to none. Because of this, fingertip replantations often entail a single arterial anastomosis without any venous anastomosis. The consequent venous congestion is addressed by external bleeding procedures, such as fish-mouth incisions, dermal de-epithelization, nailhole punctures, and manual squeezing. However, simple external bleeding methods often fail due to blood clotting, and require anticoagulation (e.g., local subcutaneous heparin treatment, a heparinized saline drip, or leech therapy).

In previous studies, the number of venous anastomoses was not associated with higher rates of replant survival in Tamai zone I amputations. In the study by Matsuda et al. [11], greater numbers of venous anastomoses were associated with increased survival of middle phalangeal replantations. However, those authors also reported that an increased number of venous anastomoses was not associated with increased survival for fingertip replantations, demonstrating that a lack of venous anastomoses can still result in a viable replanted fingertip. In a more recent study, Efanov et al. [9] evaluated the relationship between the number of venous anastomoses and the survival of replanted digits at all amputation levels, and found that multiple venous anastomoses were associated with the least likelihood of replant failure. However, the subgroup analysis consisting only of Tamai zone I amputations did not show any relationship between the number of venous repairs and the survival rate. Our study results echoed the findings of both Matsuda et al. and Efanov et al. in that survival rates were high for fingertip replantations regardless of the number of venous anastomoses. This was most likely because external bleeding (with or without leech therapy) was used for replantations without any venous anastomoses.

One key finding from our study was that a greater number of venous anastomoses was associated with a significantly lower rate of external bleeding. In the group with no venous anastomoses (group 1), external bleeding was performed in $50.7 \%$ of the replanted digits, whereas external bleeding was performed in $19.4 \%$ of the replanted digits with 2 or more venous anastomoses (group 3). In clinical practice, this represents an absolute reduction of $30 \%$ in the need for external bleeding after fingertip replantation. External bleeding requires observation of the bleeding site every 1-2 hours by trained healthcare personnel, and multiple venous anastomoses can reduce the burden of in- 
tensive postoperative monitoring, which represents a strong economic incentive for overcoming the technical challenges of venous anastomosis [10].

This relationship between the number of venous anastomoses and the frequency of external bleeding, however, should be interpreted in the context of our institutional approach to fingertip replantation, which is to attempt venous repair for all possible anatomic configurations. In our study, venous anastomosis was attempted but not performed because of a total lack of available veins in group 1. For further detail, we invite readers to consult the discussion in a separate publication dedicated to this topic [12]. Because of the attempt-all-anastomoses approach at our institution, we believe that our dataset represents the utmost technical limits of venous anastomosis and that external bleeding will be required in $40.6 \%$ ( 58 of 143 ) of all Tamai zone I replantations even when attempting venous anastomosis in all circumstances.

An interesting observation is that, among the 69 artery-only replantations, half of the replanted digits did not require external bleeding (49.3\%) and that all these digits remained viable prior to neovascularization. Generally, salvage procedures are employed for venous congestion following artery-only anastomosis. However, external bleeding does not change the survival outcomes if the diameter of the artery is less than $0.5 \mathrm{~mm}$. In a study on fingertip replantation, Cheng et al. [13] found that artery-only anastomosis was associated with better surgical outcomes than composite grafts, although neither venous anastomosis or external bleeding occurred.

Our study does have a few significant limitations. The retrospective nature of the study precludes any interpretation of the data beyond associations. Despite the high replant survival rate, the fact that no veins were available for anastomosis in group 1 probably means that the amputations in group 1 were more likely to involve more distal or severely injured amputated tissue. Another significant limitation is that our study presents experiences from a single institution, in which digital replantations have been performed daily for the past 20 years. Because of this, Tamai zone I outcomes are likely to be worse-with a higher external bleeding rate and lower replant survival rate-at institutions with a lower volume.

\section{CONFLICT OF INTEREST}

No potential conflict of interest relevant to this article was reported

\section{REFERENCES}

1. Panattoni JB, De Ona IR, Ahmed MM. Reconstruction of fingertip injuries: surgical tips and avoiding complications. J Hand Surg Am 2015;40:1016-24.

2. Foucher G, Henderson HR, Maneau M, et al. Distal digital replantation: one of the best indications for microsurgery. Int J Microsurg 1981;3:263-70.

3. Rusch MD, Grunert BK, Sanger JR, et al. Psychological adjustment in children after traumatic disfiguring injuries: a 12-month follow-up. Plast Reconstr Surg 2000;106:1451-8.

4. Matsuzaki H, Yoshizu T, Maki Y, et al. Functional and cosmetic results of fingertip replantation: anastomosing only the digital artery. Ann Plast Surg 2004;53:353-9.

5. Buntic RF, Brooks D. Standardized protocol for artery-only fingertip replantation. J Hand Surg Am 2010;35:1491-6.

6. Erken HY, Takka S, Akmaz I. Artery-only fingertip replantations using a controlled nailbed bleeding protocol. J Hand Surg Am 2013;38:2173-9.

7. Chen KK, Hsieh TY, Chang KP. Tamai zone I fingertip replantation: is external bleeding obligatory for survival of artery anastomosis-only replanted digits? Microsurgery 2014;34:535-9.

8. Huang HF, Yeong EK. Surgical treatment of distal digit amputation: success in distal digit replantation is not dependent on venous anastomosis. Plast Reconstr Surg 2015;135:1748.

9. Efanov JI, Rizis D, Landes G, et al. Impact of the number of veins repaired in short-term digital replantation survival rate. J Plast Reconstr Aesthet Surg 2016;69:640-5.

10. Aksoy A, Gungor M, Sir E. Fingertip replantation without and with palmar venous anastomosis: analysis of the survival rates and vein distribution. Ann Plast Surg 2017;78:62-6.

11. Matsuda M, Chikamatsu E, Shimizu Y. Correlation between number of anastomosed vessels and survival rate in finger replantation. J Reconstr Microsurg 1993;9:1-4.

12. Kim JS, Yang JW, Lee DC, et al. Challenges in fingertip replantation. Semin Plast Surg 2013;27:165-73.

13. Cheng L, Chen K, Chai YM, et al. Fingertip replantation at the eponychial level with venous anastomosis: an anatomic study and clinical application.J Hand Surg Eur Vol 2013;38:959-63. 